\title{
Timing of Fungicide Applications for Control of Husk Spot Caused by Pseudocercospora macadamiae in Macadamia
}

\author{
O. A. Akinsanmi, A. K. Miles, and A. Drenth, Tree Pathology Centre, The University of Queensland and Depart- \\ ment of Primary Industries and Fisheries, Indooroopilly, Qld 4068, Brisbane, Australia
}

\begin{abstract}
Akinsanmi, O. A., Miles, A. K., and Drenth, A. 2007. Timing of fungicide applications for control of husk spot caused by Pseudocercospora macadamiae in macadamia. Plant Dis. 91:16751681.

Pseudocercospora macadamiae is an important pathogen of macadamia in Australia, causing a disease known as husk spot. Growers strive to control the disease with a number of carbendazim and copper treatments. The aim of this study was to consider the macadamia fruit developmental stage at which fungicide application is most effective against husk spot, and whether application of copper-only applications at full-size fruit developmental stage toward the end of the season contributed to effective disease control. Fungicides were applied to macadamia trees at four developmental stages in three orchards in two subsequent production seasons. The effects of the treatments on disease incidence and severity were quantified using area under disease progress curve (AUDPC) and logistic regression models. Although disease incidence varied between cultivars, incidence and severity on cv. A16 showed consistent differences between the treatments. Most significant reduction in husk spot incidence occurred when spraying commenced at match-head sized-fruit developmental stage. All treatments significantly reduced husk spot incidence and severity compared with the untreated controls, and a significant positive linear relationship $\left(R^{2}=73 \%\right)$ between AUDPC and severity showed that timing of the first fungicide application is important for effective disease control. Application of fungicide at full-size fruit stage reduced disease incidence but had no impact on premature fruit drop.
\end{abstract}

Additional keywords: chemical control, disease management, fungi, Macadamia integrifolia, $M$. tetraphylla, tree nut

Husk spot, caused by Pseudocercospora macadamiae Beilharz, Mayers \& Pascoe (1), is a serious disease of Macadamia integrifolia Maiden and Betche, its cultivars and hybrids with $M$. tetraphylla L. A. S. Johnson being the most important in Australia. The disease has not been reported from any other macadamiaproducing nations outside Australia, including the United States, Kenya, Costa Rica, Malawi, and South Africa. Since yield loss in macadamia due to husk spot was first reported in 1981, it has become an economically important disease in the rapidly growing macadamia industry in Australia, and its distribution now spans the entire production area on the east coast. In the absence of effective disease control, yield losses may be up to 30 to $40 \%$ (5). A major part of the economic impact is caused by premature fruit abscission when the kernels are still immature and of low oil content, making them unsuitable for processing and consumption. Further pro-

Corresponding author: O. A. Akinsanmi

E-mail: uqoakins@uq.edu.au

Accepted for publication 11 July 2007.

doi:10.1094/PDIS-91-12-1675

(C) 2007 The American Phytopathological Society duction quality issues arise due to the harvesting of a mixture of mature and immature nuts, giving rise to inefficiencies at the sorting and processing stage.

Premature fruit abscission in macadamia occurs naturally at three different periods: (i) abscission of pollinated but unfertilized flowers 2 weeks after flowering, (ii) abscission of young fertilized fruit at 3 to 8 weeks post anthesis, and (iii) abscission of developing fruit due to physiological factors from 10 weeks after anthesis $(9,11,15)$. Abscission of mature fruit commences approximately 30 weeks post anthesis, at which point fruit are harvested from the ground (16). Oil content of mature kernels should be a minimum of $72 \%$ before they can be classified as premium or grade-one kernels. Significant loss of yield and quality due to husk spot may occur between 10 and 28 weeks post anthesis. Adverse climatic conditions, including high temperature and water stress, poor tree nutrition, and limitations in storage carbohydrate mobility, also may affect fruit abscission in macadamia and may be responsible for variable yields $(12,13$, 15,16).

In the southern hemisphere, macadamia cultivars flower mainly in September and October $(1,7)$. The developing fruit is made up of the husk or pericarp enclosing the seed coat (shell) and the embryo (ker- nel). The husk is initially soft and green and, as the fruit matures, it becomes harder, dry, and finally splits or dehusks, exposing the nut at or near harvest $(2,7)$. At this time, the nut is brown and hard and contains the edible kernel. The seed coat or shell of the nut is cracked open to obtain the edible kernel. Husk spot is the only disease that naturally affects macadamia husk prior to reaching maturity. Initial spots are chlorotic, often visible on the husk in December and January on trees that flowered during the main flowering period in August. The chlorotic spots (2 to $5 \mathrm{~mm}$ ) with a diffuse pale green halo which merges with the husk's green color is easily distinguished from other husk diseases caused by other fungi such as Colletotrichum spp., Phomopsis spp., and Lasiodiploida spp. (5). The necrotic spot phase, in which the spots turns pale tan to brown and hard, leaving a chlorotic margin as the lesion enlarges to 5 to $15 \mathrm{~mm}$, is more evident on 4- to 5-month-old fruit (1). Unlike lesions caused by other fungi, husk spots are never black or spongy (5). Sporulation occurs in this necrotic area about 10 weeks after the spot was first visible as a chlorotic spot. These brown and necrotic lesions may be covered with a thin layer of external hyphae that may produce secondary inoculum. P. macadamiae conidia are produced on diseased husks during damp, humid weather with a temperature range of 16 to $29^{\circ} \mathrm{C}$. Dissemination of this inoculum is believed to occur by rain splash or through windblown conidia from old diseased husks that remain attached to the pedicel on the tree. The incubation time from infection to expression of the first visible chlorotic symptoms may take 39 to 54 days (5).

Macadamia cultivars show differences in their fruit drop pattern and in their ability to retain fruit in the canopy after they have reached maturity. Infection of the husk by $P$. macadamiae promotes fruit drop, and this changes the fruit drop pattern compared with healthy fruit. Cultivars that retain the diseased fruit until kernels are mature are regarded as tolerant or resistant to fruit drop, whereas cultivars with low disease incidence in the field are defined as resistant to the establishment of the pathogen. Information on resistance of different cultivars and tolerance to fruit drop has not been accurately quantified. In order to select for resistance to husk spot, a robust method for assessment is needed to 
accurately quantify incidence, severity, and economic impact through yield loss in cultivars. For the purpose of this article, we define husk spot incidence as the number of fruit that are visibly diseased with one or more lesions $(3,10)$. Twenty-five fruit were evaluated on different sections of the tree, with a total of 100 fruit per tree. We have defined disease severity as the amount of abscised fruit visibly diseased relative to the total fruit abscised (3). Yield loss was defined as weight of nuts from abscised fruit that contained kernels with $<72 \%$ oil content. Accurate quantification of husk spot incidence, severity, and yield loss was needed to allow for accurate and quantifiable assessment of currently available cultivars as well as breeding lines within the current breeding program.

Despite the use of carbendazim and copper fungicides, husk spot continues to increase in severity and spread to new orchards where extensive losses from husk spot are reported to occur. In order to aid growers in reducing disease, a calendar spray regime with tank mixture of carbendazim and copper was developed. However, more information to better understand the time of infection and disease spread will help to guide fungicide applications. The current chemical control system is based on a total of four sprays at 4week intervals, with the first two sprays containing carbendazim and copper applied in October when the fruit is at the pea-size stage of fruit development and the last two containing only copper. The overall goal of this study was to establish the most effective time for fungicide application to control husk spot and determine the effectiveness and the need to apply protectant copper fungicide when the macadamia fruit have reached mature size. The specific aims of the study were to (i) determine the most effective growth stage of macadamia fruit to start the application of fungicides for husk spot control, (ii) evaluate the effectiveness of the last two copperonly applications on the severity of husk spot, and (iii) determine whether husk spot incidence is correlated to dropping of immature fruit. Informed decisions on the correct timing of fungicide application based on developmental stages of flowers and fruit supported by an understanding of the biology of the fungus are essential for improvement of husk spot disease management.

\section{MATERIALS AND METHODS}

Field sites and experimental design. Experiments were conducted on 'Hidden Valley A16' (A16), a commercial cultivar that is widely grown in Australia and commonly found with husk spot (5). Field sites, representing the three major production regions in Australia, were located at Bangalow, New South Wales (NSW) $\left(28^{\circ} 69^{\prime} \mathrm{S}, 1^{\circ} 3^{\circ} 52^{\prime} \mathrm{E}\right)$; Beerwah, Queensland $\left(26^{\circ} 85^{\prime} \mathrm{S}, 152^{\circ} 95^{\prime} \mathrm{E}\right)$; and Bundaberg, Queensland $\left(24^{\circ} 87^{\prime} \mathrm{S}, 152^{\circ} 35^{\prime} \mathrm{E}\right)$. An additional commercial cultivar, HAES 246, also widely grown in NSW, was included at Bangalow. Five different treatments, including an untreated control, were assigned to plots in a randomized design with three replicates at each site. Each plot contained 15 trees arranged in three rows of 5 trees. Data were recorded separately from each of the three middle trees from each plot, while the other trees served as buffer trees to prevent spray drifts between treatments. The experiments were conducted in an A16 block of 164 trees in Beerwah. At Bundaberg, rows contained mixed cultivars and a total of 285 trees; a block containing at least nine sets of 3 A16 trees together was used. A block with parallel rows of A16 and HAES 246 together gave a total of 243 trees in Bangalow. The total number of data trees was 45 in Beerwah and Bundaberg and 90 in Bangalow. All trees received similar agronomic practices and insect control. Insect populations were monitored by pest scouts and controlled by the application of insecticide sprays. The experiments were conducted in the 2004-05 macadamia production season and repeated in the 2005-06 season.

Timing of fungicide applications. In order to determine the most effective growth stage for the first fungicide application, time-spraying trials using the industry standard (IS) fungicides of a tankmixture of carbendazim (SpinFlo; Bayer CropScience, Australia) and copper oxide
(Nordox 500 copper; Swift \& Company Limited, Australia) were conducted in the 2004-05 and 2005-06 season. All fungicides were applied at 4-week intervals (Table 1). Three treatments consisting of two sprays of carbendazim tank-mixed with copper, followed by two copper-only sprays, commencing at either match-headsized fruit stage (Early), at pea-size fruit stage, which is considered industry standard (IS), or 4 weeks after pea-size fruit stage (Late) were applied. A fourth treatment was included, commencing at peasize fruit stage, consisting of two carbendazim tank-mixed with copper sprays, but without the last two copper-only applications (IS-no-Cu) to address the question concerning the effectiveness of these two late-copper-only applications (Table 1). Plots that received no chemical applications served as untreated controls. Macadamia trees were monitored from beginning of anthesis to determine the developmental stage of flowers and fruit development. Chemicals were applied using commercial spraying equipment (Silvan Supaflo, 2,000 liters) at 20 to 30 $\mathrm{kPa}$ with an application volume of approximately 3 liters per tree to a tree canopy volume range of 80 to $85 \mathrm{~m}^{3}$. No surfactant or spreader was added to the chemicals, which were used as a concentrate spray of $0.1 \mathrm{~g}$ of active ingredient for carbendazim and $4 \mathrm{~g}$ for Nordox per liter.

Disease incidence. In order to evaluate the efficacy of the treatments, husk spot incidence was monitored over time during the season. Developing fruit were observed weekly for husk spot symptoms from match-head fruit stage, with young fruit about $2 \mathrm{~mm}$ in diameter or about the size of a match-head. At 2-week intervals from the end of January to early March, the incidence of husk spot was assessed on 25 arbitrarily selected fruit from each of the four canopy aspects (within and between rows), for each data tree, totaling 100 fruit per tree. The proportion of diseased fruit was used to represent disease incidence. The incidence was averaged over the three individual trees within each plot and plotted against time to produce a disease progress curve.

Table 1. Timing of application of cabendazim (Spin) and copper oxide ( $\mathrm{Cu}$ ) on macadamia cultivars in the 2004-05 and 2005-06 seasons

\begin{tabular}{|c|c|c|c|c|c|c|c|}
\hline \multirow[b]{2}{*}{$\mathbf{W P A}^{\mathrm{z}}$} & \multirow[b]{2}{*}{ Fruit diameter (mm) } & \multirow[b]{2}{*}{ Developmental fruit stage } & \multicolumn{5}{|c|}{ Treatment $^{y}$} \\
\hline & & & Early & IS & Late & IS-no-Cu & Control \\
\hline 4 & $<2$ & Match-head & $\mathrm{Spin}+\mathrm{Cu}$ & $\ldots$ & $\ldots$ & & $\ldots$ \\
\hline 6 & $2-5$ & Pea size & $\ldots$ & $\mathrm{Spin}+\mathrm{Cu}$ & $\ldots$ & $\mathrm{Spin}+\mathrm{Cu}$ & $\ldots$ \\
\hline 8 & $5-10$ & Advanced pea size & $\mathrm{Spin}+\mathrm{Cu}$ & & $\ldots$ & & $\ldots$ \\
\hline 10 & $10-15$ & Medium size & 1 & $\mathrm{Spin}+\mathrm{Cu}$ & $\ldots$ & $\mathrm{Spin}+\mathrm{Cu}$ & $\ldots$ \\
\hline 12 & $15-20$ & Full size & $\mathrm{Cu}$ & $\ldots$ & $\mathrm{Spin}+\mathrm{Cu}$ & $\ldots$ & $\cdots$ \\
\hline 14 & $20-30$ & Mature size & $\ldots$ & $\mathrm{Cu}$ & $\ldots$ & $\cdots$ & $\cdots$ \\
\hline 16 & $>30$ & Mature size & $\mathrm{Cu}$ & $\ldots$ & $\mathrm{Spin}+\mathrm{Cu}$ & $\ldots$ & $\ldots$ \\
\hline 18 & $>30$ & Mature size & $\ldots$ & $\mathrm{Cu}$ & $\ldots$ & $\ldots$ & $\ldots$ \\
\hline 20 & $>30$ & Mature size & $\ldots$ & $\ldots$ & $\mathrm{Cu}$ & $\ldots$ & $\ldots$ \\
\hline 24 & $>30$ & Mature size & $\ldots$ & $\ldots$ & $\mathrm{Cu}$ & $\ldots$ & $\ldots$ \\
\hline
\end{tabular}

y IS = industry standard and Control = untreated control.

${ }^{\mathrm{z}}$ Weeks post anthesis. 
Disease severity. To assess the severity of husk spot on macadamia trees, all fruit that dropped from each tree between late January and early March (preharvest fruit drop) were collected the same day as the disease incidence was recorded. In both the 2004-05 and 2005-06 season, the dropped fruit were classified into two categories: diseased (with lesions caused by $P$. macadamiae) and others (undamaged and lesion free, injured by insects, rats, or pathogens other than $P$. macadamiae) and the weight of fruit in the two categories recorded. Thereafter, fruit in the two categories was pooled for each data tree and the weight of wet nuts recorded. Nuts were obtained after the husk or pericarp has been removed, revealing a hard, brown shell enclosing the kernel. Nuts per tree were dried in fan-forced laboratory ovens for 2 days each at 38,45 , and $55^{\circ} \mathrm{C}$ to approximately $1.5 \%$ moisture content and the weights of dried nuts recorded. Approximately 100 nuts were cracked using a tabletop cracking machine and the oil content of the kernels, a measure of commercial maturity, was determined using a standard flotation method (4).

Data analysis. The area under disease progress curve (AUDPC) was calculated from disease incidence data by using the formula:

$$
\text { AUDPC }=\sum_{i=1}^{a}\left(\left\{\left[Y_{i}+Y_{(i+1)}\right] / 2\right\} \times\left[t_{i+1}-t_{i}\right]\right)
$$

where $Y_{i}=$ disease level at time $t_{i}$, and $\left(t_{(i+1)}-t_{i}\right)=$ Time (days) between two disease incidence scores. Cumulative weight of the preharvest nuts recorded for diseased fruit at each collection date served as a measure of disease severity. AUDPC and severity data were square root transformed to stabilize variance. To determine whether there were significant differences between years, field sites, treatments (time of fungicide application), and their interactions, a three-way factorial analysis of variance (ANOVA) first was performed using GenStat (release 8.1; Lawes Agricultural Trust, Rothamsted Experimental Station, UK) on the AUDPC and severity data. Significant factors were separated and tested using Fisher's protected least significant difference (LSD) tests. Treatment effects of the AUDPC data related to the time of fungicide application were analyzed using the linear regression model. The quadratic term of the model was explored by the polynomial regression procedure in GenStat using the model Pred $(a u d p c)=a+\delta$ $+\beta(t)+\gamma\left(t^{2}\right)$, where $a$ is a constant, $\delta$ the site effect, and $\beta$ and $\gamma$ are the time of fungicide application effects for linear and quadratic terms, respectively. The treatment effects in the severity data were analyzed by the logistic model function
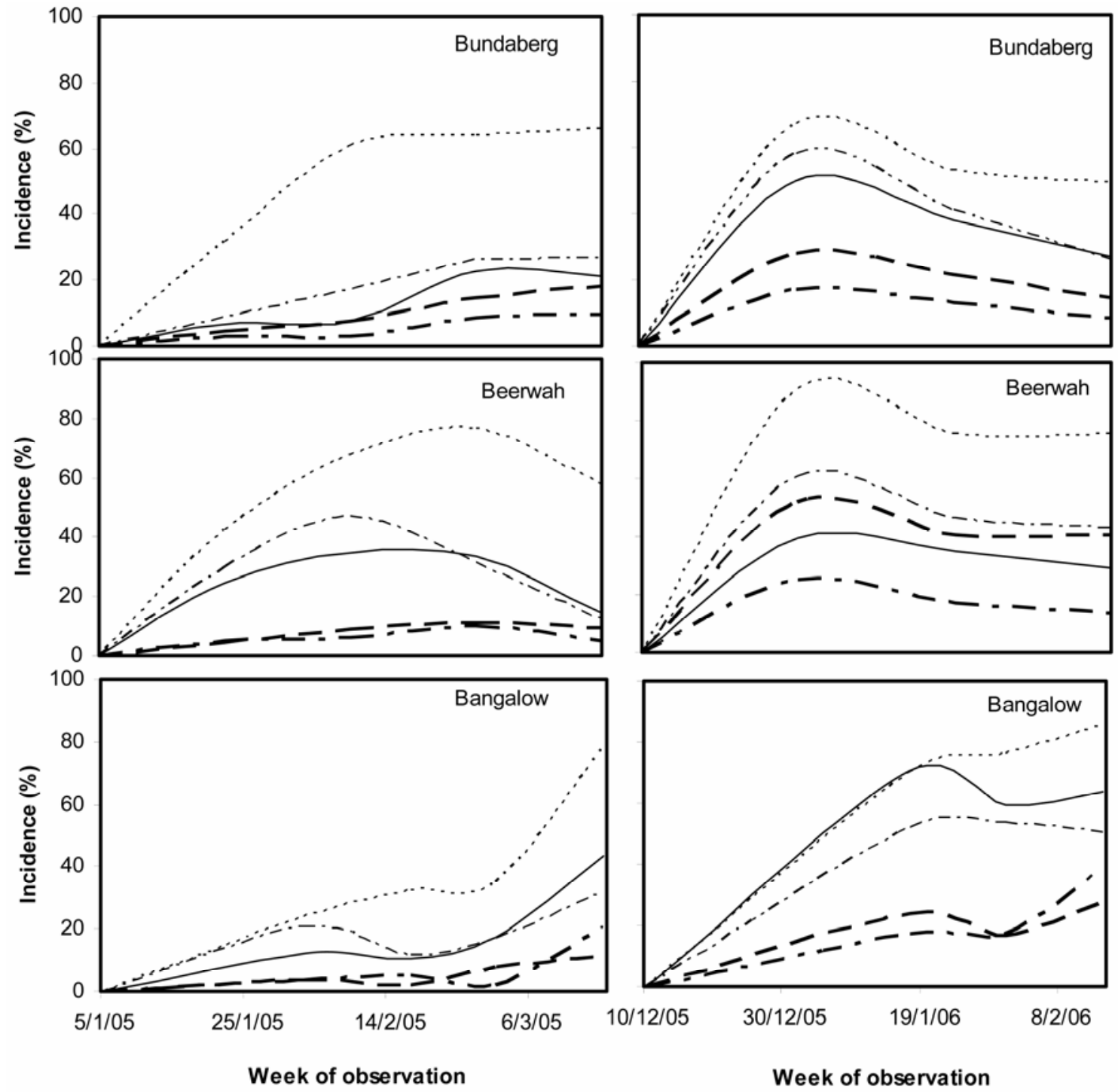

- - IS - - Early

-.-.- Late

IS-no-Cu

Week of observation

Fig. 1. Disease progress curves showing the incidence of husk spot on macadamia (cv. A16) in field experiments at three different locations in the 2004-05 and 2005-06 production seasons in response to application of Carbendazim and copper fungicides at different developmental stages: match-head (Early), pea size (industry standard [IS]), 4 weeks after IS (Late), IS without copper sprays (IS-no-Cu), and an untreated control. 
using the IS treatment as the reference level.

\section{RESULTS}

Disease incidence. The first fungicide application (Early) was applied in the second week of October in both the 2004-05 and 2005-06 seasons, when the majority of the developing fruit were at match-head stage (ovary approximately $2 \mathrm{~mm}$ in diameter). Climatic conditions were favorable for husk spot disease in both seasons.
The seasonal mean daily maximum temperatures ranged from 25.3 to $30.9^{\circ} \mathrm{C}$ in the $2004-05$ season and 25.3 to $32.7^{\circ} \mathrm{C}$ in the 2005-06 season, whereas the monthly rainfall ranged from 16 to $212 \mathrm{~mm}$ in the 2004-05 season and 56 to $526 \mathrm{~mm}$ in the 2005-06 season. Almost no husk spot symptoms were observed on HAES 246 in both years. Therefore, the results presented and discussed in this article are those obtained only from A16 from all the three field sites.

Table 2. Results of the polynomial regression analysis of area under disease progress curve of husk spot incidence on macadamia cv. A16 treated with Carbendazim and copper oxide at different times after anthesis in three fields

\begin{tabular}{lccl}
\hline Regression parameter $^{\mathbf{y}}$ & Estimate $^{\mathbf{z}}$ & $\boldsymbol{t}_{\mathbf{( 8 5 9 )}}$ & $\boldsymbol{t} \mathbf{p r} \mathbf{~}$ \\
\hline Time of application effect (44.0\%) & $12.3(20.2)$ & 0.61 & 0.54 \\
$\quad$ Constant & $11.2(18.5)$ & 0.61 & 0.54 \\
Linear & $14.5(3.6)$ & 3.99 & 0.001 \\
Quadratic & $11.2(17.9)$ & 0.62 & 0.53 \\
Time of application + site effect (47.1\%) & $14.5(3.5)$ & 4.1 & 0.001 \\
Time (Linear) & $-1.8(20.3)$ & -0.09 & 0.93 \\
Time (Quadratic) & $48.3(20.3)$ & 2.38 & 0.02 \\
Site - Bundaberg & $-9.4(20.3)$ & -0.47 & 0.64 \\
Site - Beerwah & & \\
Site - Bangalow &
\end{tabular}

${ }^{\mathrm{y}}$ Value in parentheses indicates percentage of total variance explained.

${ }^{\mathrm{z}}$ Values in parentheses indicate standard error.

Table 3. Analysis of variance of the area under disease progress curve of incidence of husk spot on macadamia cv. A16 treated with Carbendazim and copper oxide at different times in three sites during the 2004-05 and 2005-06 growing seasons

\begin{tabular}{lcccc}
\hline Source & $\mathbf{d f}^{\mathbf{z}}$ & $\begin{array}{c}\text { Mean } \\
\text { square }\end{array}$ & $\begin{array}{c}\text { Variance } \\
\text { ratio }\end{array}$ & $\boldsymbol{F}<\boldsymbol{P}$ \\
\hline Replicate & 2 & 1,847 & 0.2 & 0.800 \\
Year & 1 & $1,652,961$ & 199.6 & $<0.001$ \\
Treatment & 4 & $1,936,055$ & 233.8 & $<0.001$ \\
Site & 2 & 471,371 & 56.9 & $<0.001$ \\
Year $\times$ treatment & 4 & 115,799 & 14.0 & $<0.001$ \\
Year $\times$ site & 2 & 48,921 & 5.9 & 0.003 \\
Treatment $\times$ site & 8 & 63,562 & 7.7 & $<0.001$ \\
Year $\times$ treatment $\times$ site & 8 & 77,019 & 9.3 & $<0.001$ \\
\hline
\end{tabular}

${ }^{\mathrm{z}}$ Degrees of freedom

Table 4. Comparison of means of area under disease progress curve of husk spot incidence on macadamia trees cv. A16 treated with Carbendazim and copper oxide $(\mathrm{Cu})$ at four different times after anthesis in the 2004-05 and 2005-06 growing seasons

\begin{tabular}{|c|c|c|c|}
\hline Field site, treatment ${ }^{y}$ & 2004-05 & 2005-06 & $2004-05$ vs. 2005-06 $(P>F)^{\mathrm{z}}$ \\
\hline \multicolumn{4}{|l|}{ Beerwah } \\
\hline Early & $37.3 \mathrm{c}$ & $37.4 \mathrm{c}$ & $\mathrm{ns}$ \\
\hline Industry standard (IS) & $45.5 \mathrm{c}$ & $207.9 \mathrm{~b}$ & $* *$ \\
\hline IS-no-Cu & $138.6 \mathrm{~b}$ & $269.7 \mathrm{~b}$ & $* *$ \\
\hline Late & $143.3 \mathrm{~b}$ & $281.7 \mathrm{~b}$ & $* *$ \\
\hline Untreated control & $340.8 \mathrm{a}$ & $386.1 \mathrm{a}$ & $\mathrm{ns}$ \\
\hline \multicolumn{4}{|l|}{ Bundaberg } \\
\hline Early & $44.5 \mathrm{~d}$ & $60.8 \mathrm{~d}$ & $\mathrm{~ns}$ \\
\hline IS & $74.1 \mathrm{~cd}$ & $103.7 \mathrm{c}$ & $\mathrm{ns}$ \\
\hline IS-no-Cu & $123.8 \mathrm{~b}$ & $185.4 \mathrm{~b}$ & $* *$ \\
\hline Late & $109.3 \mathrm{bc}$ & $200.5 \mathrm{~b}$ & ** \\
\hline Untreated control & $213.3 \mathrm{a}$ & $273.1 \mathrm{a}$ & $* *$ \\
\hline \multicolumn{4}{|l|}{ Bangalow } \\
\hline Early & $26.9 \mathrm{c}$ & $19.2 \mathrm{~d}$ & $\mathrm{~ns}$ \\
\hline IS & $30.9 \mathrm{c}$ & $100.9 \mathrm{c}$ & $* *$ \\
\hline IS-no-Cu & $74.3 \mathrm{~b}$ & $92.5 \mathrm{c}$ & ns \\
\hline Late & $97.8 \mathrm{~b}$ & $219.2 \mathrm{~b}$ & ** \\
\hline Untreated control & $143.7 \mathrm{a}$ & $379.5 \mathrm{a}$ & $* *$ \\
\hline
\end{tabular}

y Early $=$ match-head fruit stage, IS $=$ pea-size, and Late $=4$ weeks after IS.

${ }^{\mathrm{z}}$ Value with $* *$ indicates significant at $P<0.05$ and ns indicates not significant according to Fisher's protected least significant different test.

In the 2004-05 field trials, husk spot symptoms first were noticed as chlorotic flecks in the untreated control plots on 5 January 2005, whereas they first were noticed on 10 December 2005 in the 200506 trial. Disease progress curves for all treatments at the three field sites are shown in Figure 1. Although the disease incidence varied between years, it occurred at about the same time in the three sites within both seasons (Fig. 1). Husk spot developed throughout the period of the trials in both years. The disease progress curves of the different treatments followed a similar pattern within each field site. The positive slope of the curves indicates increasing disease incidence over time. The apparent decline in the curves is due to the extensive abscission of diseased, immature fruit during this period which may give rise to a decline in disease incidence, which we defined as the proportion of diseased fruit remaining on the tree.

Disease incidence increased as the first fungicide application was delayed (Fig. 1). The linear regression model showed that a significant positive relationship exists between husk spot incidence and time of application. The effect of time of application on husk spot incidence explained $44 \%$ of the variation whereas field site explained $3.1 \%$. Therefore, the linear regression model with time of application $(\operatorname{Pred}[a u d p c]=-60.13+83.68 t$, where $t=$ time of fungicide application) was sufficient to explain the factor affecting husk spot control. Addition of a quadratic term only marginally improved the model (Table 2).

The ANOVA showed significant variation between years, treatments, sites, and their interactions, but no significant difference occurred between the replicates (Table 3). There was no difference in the Early treatment for both years in all three sites (Table 4). Although there were significant three-way interactions between year, treatment, and site, the disease incidence in untreated control treatments, in all cases, was significantly higher than any of the treatments. Ranking of effectiveness to reduce the disease incidence after the untreated control subsequently was Late, IS-no- $\mathrm{Cu}$, and IS, with the Early treatment having the lowest disease incidence for all sites in both years (Table 4).

Disease severity. Preharvest fruit under each data tree was examined for husk spot symptoms. The cumulative weight of total fruit (diseased and healthy) and diseased fruit collected varied significantly between years and among treatments (Table 5). However, no significant differences were observed between the sites and their interactions with treatment and year (Table 5). Preharvest fruit drop patterns followed the same pattern as the disease incidence, giving rise to a positive slope of the curves for all treatments (Fig. 2). The amount of nuts that dropped increased over time and 
increased with the time after anthesis that fungicide application was delayed. This trend also was described by a linear regression model that showed a significant positive relationship between preharvest nuts and time of application: $P_{n}=4.7+$ 4.3 $(t)$, where $P_{n}$ is the weight of preharvest nuts and $t$ is the time of fungicide application. However, only $12.7 \%$ of the total variance is explained by the time effect, and the addition of a quadratic term did not significantly $(P=0.424)$ improve the model.

The amount of preharvest diseased fruit was higher in the 2005-06 season than the 2004-05 season (Table 6). The amount of immature nuts that dropped due to husk spot was highest for the untreated control followed by Late and IS-no-Cu treatments in both the 2004-05 and 2005-06 seasons (Table 6). Using IS treatment as the reference level, the logistic models showed that only the Early treatment applied at matchhead stage recorded a significant improvement over the IS concerning disease incidence and disease severity (data not shown). Analyses of the kernel maturity

Table 5. Analysis of variance of husk spot severity based on the weight of nuts from diseased fruit that dropped before normal harvest compared with healthy and total preharvest fruit drop in field experiments conducted in three locations during the 2004-05 and 2005-06 macadamia production seasons to the time of application of Carbendazim ${ }^{\mathrm{y}}$

\begin{tabular}{|c|c|c|c|c|c|c|c|}
\hline \multirow[b]{2}{*}{ Source of variation } & \multirow[b]{2}{*}{$d_{f^{2}}$} & \multicolumn{2}{|c|}{ Diseased nuts } & \multicolumn{2}{|c|}{ Healthy nuts } & \multicolumn{2}{|c|}{ Total nuts } \\
\hline & & Mean square & $F<p$ & Mean square & $F<p$ & Mean square & $F<p$ \\
\hline Site & 2 & 117.1 & 0.153 & 6,565 & 0.071 & 89.0 & 0.261 \\
\hline Year & 1 & $1,404.6$ & $<0.001$ & 76,503 & $<0.001$ & 1191.9 & $<0.001$ \\
\hline Treatment & 4 & $1,937.8$ & $<0.001$ & 10,120 & 0.003 & $1,727.2$ & $<0.001$ \\
\hline Site $\times$ year & 2 & 6.8 & 0.897 & 20,275 & $<0.001$ & 23.8 & 0.698 \\
\hline Site $\times$ treatment & 8 & 41.5 & 0.721 & 2,578 & 0.403 & 36.3 & 0.82 \\
\hline Year $\times$ treatment & 4 & 33.5 & 0.707 & 9,868 & 0.003 & 24.7 & 0.828 \\
\hline Site $\times$ year $\times$ treatment & 8 & 24.2 & 0.927 & 3,325 & 0.218 & 31.8 & 0.87 \\
\hline
\end{tabular}

${ }^{\mathrm{y}}$ Healthy fruit include those that are undamaged and lesion free, whereas damaged fruit were those that were injured by insects, rats, or pathogens other than Pseudocercospora macadamiae.

${ }^{z}$ Degrees of freedom.
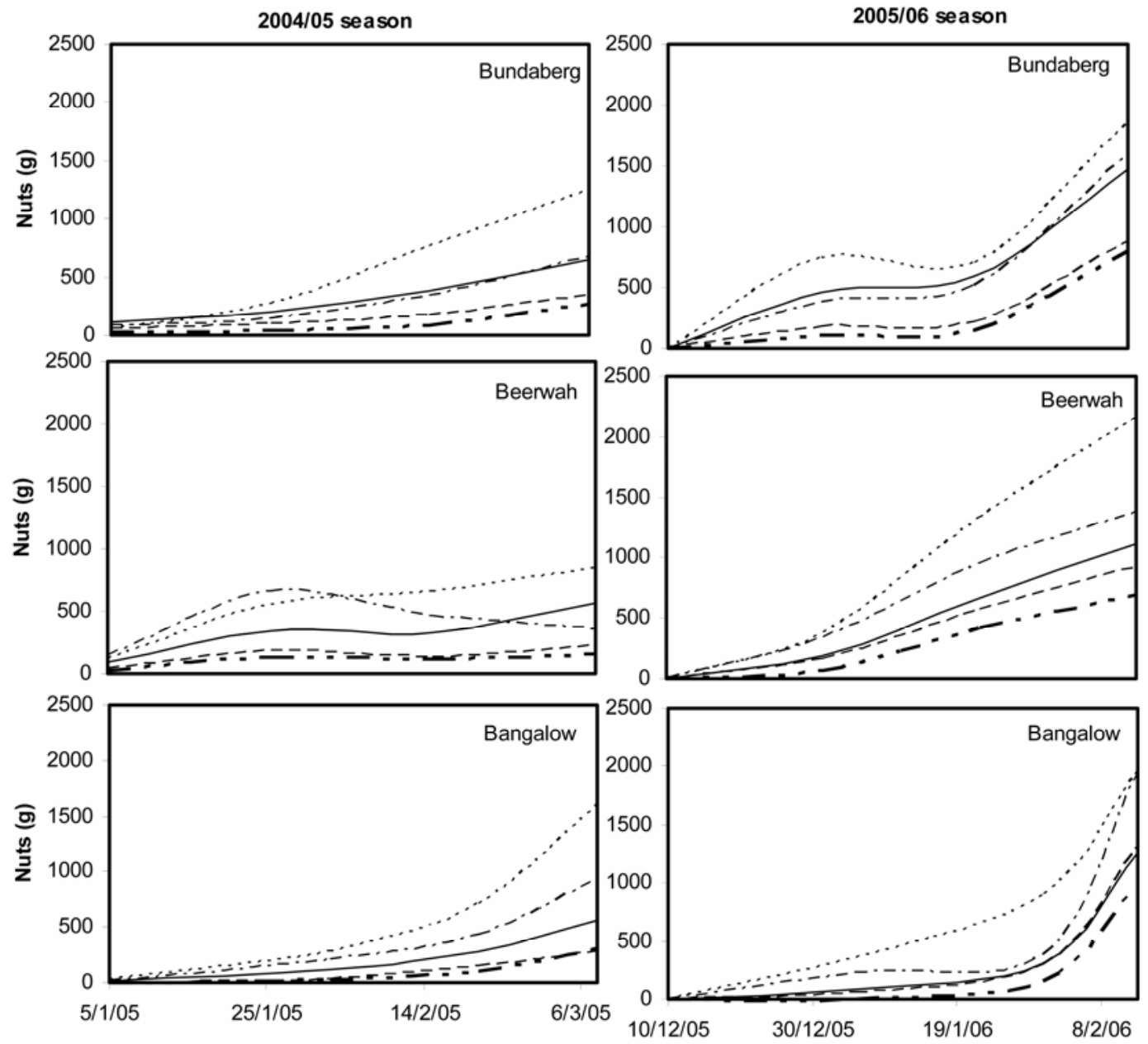

Preharvest period

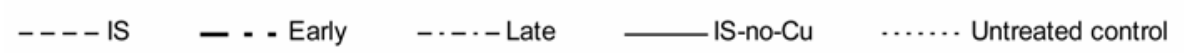

Fig. 2. Effect of time of first fungicide application on the amount of wet nuts obtained from macadamia (cv. A16) fruit that dropped before the start of the normal harvest period due to husk spot in field experiments at three different locations in the 2004-05 and 2005-06 seasons. Time of fungicide application at different developmental stages: match-head (Early), pea size (industry standard [IS]), 4 weeks after IS (Late), and IS without copper sprays (IS-no-Cu). 
showed that the fruit that dropped during this period (January to March) were largely immature. However, the percentage of immature nuts decreased from $94 \%$ in January to $11 \%$ in March in both years (data not shown).

Relationship between disease incidence and severity. The square roottransformed AUDPC was regressed on weight of immature nuts from infected fruit for both seasons to determine the possible relationship between the disease incidence and severity. The regression model showed that a positive linear relationship exists between disease incidence and severity in both the 2004-05 and 2005-06 seasons (Fig. 3). About 34 and $73 \%$ of the relationships were directly associated with the linear component in the 2004-05 and 2005-06 seasons, respec-

\section{DISCUSSION}

Early application of carbendazim and copper fungicides at the match-head stage tively (Fig. 3).

of development of macadamia fruit resulted in the lowest disease incidence and severity. Fungicide application at matchhead stage significantly reduced husk spot severity compared with the other treatments in our experiment. Starting the first fungicide applications at a later date was progressively less effective compared with starting at match-head stage. The reduced efficacy of starting fungicide applications later was evident in the positive slopes of regression equations describing the relationship between AUDPC and time of first application. These results indicate that the initial fungicide application for the control of husk spot in macadamia should be based on the fruit developmental stage rather than following a calendar spraying system, as is currently practiced in Australia. The positive significant correlation observed between husk spot incidence and preharvest fruit drop in this experiment showed that husk spot disease can cause significant yield loss through preharvest fruit drop in macadamia.

Table 6. Effect of application time on the cumulative preharvest fruit dropped $(\mathrm{kg})$ with husk spot on macadamia cv. A16 in three locations during 2004-05 and 2005-06 growing seasons ${ }^{\mathrm{y}}$

\begin{tabular}{lcccccc}
\hline & \multicolumn{3}{c}{ Field site } & & \multicolumn{2}{c}{ Production period } \\
\cline { 2 - 3 } \cline { 6 - 7 } Time of application $^{\mathbf{z}}$ & Beerwah & Bundaberg & Bangalow & & $\mathbf{2 0 0 4 - 0 5}$ & $\mathbf{2 0 0 5}-06$ \\
\hline Early & $1.3 \mathrm{~d}$ & $1.2 \mathrm{c}$ & $1.3 \mathrm{c}$ & & $1.1 \mathrm{c}$ & $1.5 \mathrm{~d}$ \\
Industry standard (IS) & $1.9 \mathrm{~cd}$ & $1.6 \mathrm{c}$ & $1.9 \mathrm{c}$ & & $1.5 \mathrm{c}$ & $2.1 \mathrm{~cd}$ \\
IS-no-Cu & $2.6 \mathrm{bc}$ & $3.2 \mathrm{~b}$ & $2.1 \mathrm{c}$ & & $2.0 \mathrm{~b}$ & $3.3 \mathrm{bc}$ \\
Late & $3.5 \mathrm{~b}$ & $3.1 \mathrm{~b}$ & $3.3 \mathrm{~b}$ & & $2.6 \mathrm{~b}$ & $4.1 \mathrm{~b}$ \\
Untreated control & $4.8 \mathrm{a}$ & $4.5 \mathrm{a}$ & $4.5 \mathrm{a}$ & & $3.4 \mathrm{a}$ & $5.8 \mathrm{a}$ \\
\hline
\end{tabular}

${ }^{y}$ Values in the same column followed by same letters are not significantly different $(P \leq 0.05)$ according to Fisher's protected least significant different test.

${ }^{\mathrm{z}}$ Early $=$ match-head fruit stage, IS $=$ pea size, and late $=4$ weeks after IS.

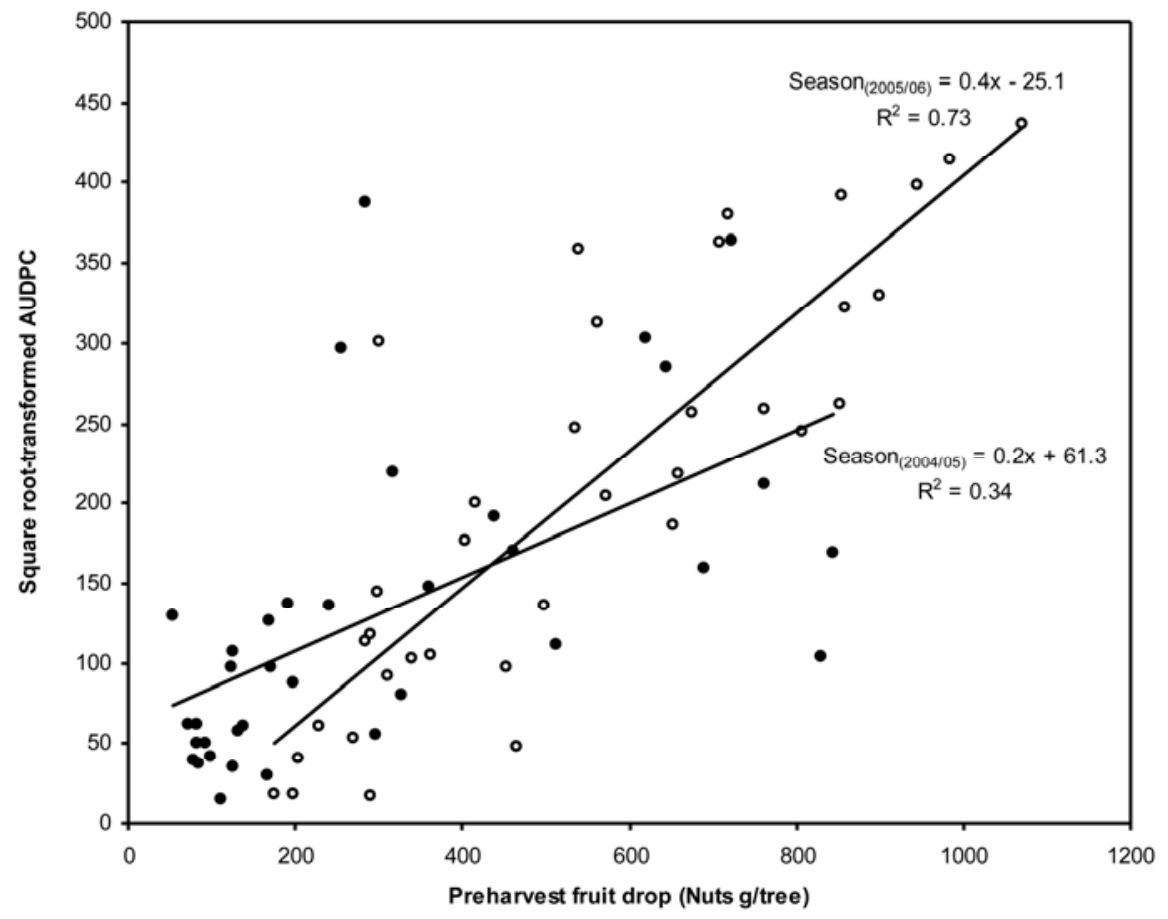

Fig. 3. Relationship between preharvest fruit drop measured as weight of wet nuts and incidence of husk spot measured as area under the disease progress curve in the 2004-05 (open circles) and 200506 (closed circles) season.
The significant interaction between sites and treatments was due to the varying performance of the IS treatment with Late and IS-no-Cu applications. This indicates that fruit are infected with $P$. macadamiae before pea-size stage and, therefore, application of protective fungicide at this and after this stage will not provide the required protection against the pathogen. The marked reduction in the husk spot incidence in all treatments over the untreated control suggests that infection still occurs on fully developed fruit. The fact that delaying the start of the first application of fungicide still provided better control of husk spot than the untreated control plots further reiterates the fact that application of fungicides at any stage of fruit development will reduce disease severity. However, application of fungicides at or near harvest (late application) will provide little, if any, economic benefit in the current growing season. This is most likely because the incubation time of the fungus is so long that kernels reach the required oil content of approximately $72 \%$ before the disease can induce fruit drop.

The application of the first carbendazim and copper spray at the match-head stage may have been highly efficacious, which raises the question of whether this is the time when the majority of infections take place in the field. The combination of these two products, a carbendazim with a systemic mode of action and a protectant copper at this time, may prevent pathogen establishment and disease development after infection has already taken place at this early stage, thus giving rise to a significant improvement in disease control. Previous studies on the effect of timing of fungicide applications on various diseases also have shown that timing of application is critical in disease control $(6,8,14,17)$. Application of a fungicide before infection is more effective in reducing disease incidence and preventing yield loss than an application after infection has already commenced or when symptoms appear, even when a systemic fungicide is used (8).

The number of applications has a significant impact on disease incidence, as indicated by the significant reduction in the disease incidence when the last two copper-only sprays were included in the fungicide regime (IS) compared with when they were not (IS-no-Cu). Congruent results were reported from studies on postbloom fruit drop of citrus caused by Colletotrichum gloeosporioides (14). However, if disease incidence was low or delayed, one or two fungicide applications applied at match-head stage and about 4 weeks later may be sufficient to reduce preharvest fruit drop. The time of the first spray is crucial; therefore, the use of systemic fungicides at this early stage may be paramount and be more beneficial than the use of protectants. The curative ability and improved protection of rapidly expanding 
tissues generally are more effectively protected by the application of a systemic product.

Previous research has shown that, when water is limited, premature fruit drop increased at high temperature $\left(30^{\circ} \mathrm{C}\right)(13)$. Although similar high temperatures were recorded between January and March in Queensland, no significant differences were recorded for the abscised fruit between the locations in Queensland and NSW. This may be because water was not limited in both 2004-05 and 2005-06 seasons in all locations. Therefore, the abscised diseased fruit observed in this study were caused by $P$. macadamiae. However, a combination of water stress and husk spot may lead to quicker dropping of the fruit. Many growers have provided anecdotal observations of increased yield loss due to the additive nature of water stress, high temperature, and husk spot. However, quantitative data are needed to substantiate this claim.

Disease incidence and severity vary among macadamia cultivars; therefore, decisions concerning the timing and frequency of applying fungicides against husk spot in macadamia will depend on several factors. These are inoculum pressure from the preceding season, climatic conditions at and immediately following anthesis, and the tolerance or resistance of each cultivar to disease and fruit drop. Calendar spraying of all macadamia cultivars regardless of the status of these conditions should be regarded as an unnecessary and expensive practice. Future field trials are needed to provide comprehensive and quantitative data on the resistance and tolerance of all current commercial cultivars and breeding lines. Together with a better understanding of the disease cycle and epidemiology of the pathogen, the provision of a knowledge-based diseaseforecasting system for determining the timing and number of fungicide applications may be possible.

\section{ACKNOWLEDGMENTS}

Horticulture Australia Limited, the Australian Macadamia Society, and the CRC for Tropical Plant Protection funded this research. We thank Fullerton farms, Kona farms, and Palmerjoy farms for the use of their orchards and their help with spraying and dehusking; without their enormous inkind contribution, this research would not have been possible; and L. Smith, J. Dean, and C. O'Dwyer for providing technical assistance.

\section{LITERATURE CITED}

1. Beilharz, V., Mayers, P. E., and Pascoe, I. G. 2003. Pseudocercospora macadamiae sp. nov., the cause of husk spot of macadamia. Australas. Plant Pathol. 32:279-282.

2. Jones, W. W. 1939. A study of developmental changes in composition of the macadamia. Plant Physiol. 14:755-768.

3. Madden, L. V., and Hughes, G. 1995. Plant disease incidence: Distribution, heterogeneity and temporal analysis. Annu. Rev. Phytopathol. 33:529-564.

4. Mason, R. L., and Wills, R. B. H. 1983. Evaluation of the use of specific gravity as an objective index of the quality of Australian macadamia nuts. Food Technol. Aust. 35:245-248.

5. Mayers, P. E. 1998. Epidemiology and control of husk spot of macadamia. Aust. Macadamia Soc. Ltd. News Bull. 25:59-64.
6. Mertely, J. C., MacKenzie, S. J., and Legard, D. E. 2002. Timing of fungicide applications for Botrytis cinerea based on developmental stage of strawberry flowers and fruit. Plant Dis. 86:1019-1024.

7. Nagao, M. A., and Hirae, H. H. 1992. Macadamia: cultivation and physiology. Crit. Rev. Plant Sci. 10:441-470.

8. Ryley, M. J., Kyei, N. A., and Tatnell, J. R. 2000. Evaluation of fungicides for the management of Sclerotinia blight of peanut. Aust. J. Agric. Res. 51:917-924

9. Sakai, W. S., and Nagao, M. A. 1985. Fruit growth and abscission in Macadamia integrifolia. Physiol. Plant. 64:455-460.

10. Seam, R. C. 1984. Disease incidence and severity relationships. Annu. Rev. Phytopathol. 22:137-150.

11. Sedgley, M. 1981. Early development of the macadamia ovary. Aust. J. Bot. 29:185-193.

12. Stephenson, R. A., Cull, B. W., and Mayer, D G. 1986. Effects of site, climate, cultivar, flushing, and soil and leaf nutrient status on yields of macadamia in southeast Queensland. Sci. Hortic. 30:227-235.

13. Stephenson, R. A., and Gallagher, E. C. 1987. Effects of temperature, tree water status and relative humidity on premature nut drop from macadamia. Sci. Hortic. 33:113-121.

14. Timmer, L. W., and Zitko, S. E. 1992. Timing of fungicide applications for control of postbloom fruit drop of citrus in Florida. Plant Dis. 76:820-823.

15. Trueman, S. J., and Turnbull, C. G. N. 1994 Effects of cross-pollination and flower removal on fruit-set in macadamia. Ann. Bot. 73:23-32

16. Trueman, S. J., and Turnbull, C. G. N. 1994. Fruit set, abscission and dry-matter accumulation on girdled branches of macadamia. Ann. Bot. 74:667-674.

17. Ward, J. M. J., Laing, M. D., and Rijkenberg, F. H. J. 1997. Frequency and timing of fungicide applications for the control of gray leaf spot in maize. Plant Dis. 81:41-48. 